\title{
Tank Applied Testing of Load-Bearing Multilayer Insulation (LB-MLI)
}

\author{
Wesley L. Johnson ${ }^{1}$ \\ NASA Glenn Research Center, Cleveland, OH, 44135, USA \\ Juan G. Valenzuela ${ }^{2}$ \\ NASA Marshall Space Flight Center, Huntsville, AL, 35812, USA \\ Jeffery R. Feller ${ }^{3}$ \\ NASA Ames Research Center, Moffett Field, CA,94035, USA \\ and \\ David W. Plachta ${ }^{4}$ \\ NASA Glenn Research Center, Cleveland, OH, 44135, USA
}

\begin{abstract}
The development of long duration orbital cryogenic storage systems will require the reduction of heat loads into the storage tank. In the case of liquid hydrogen, complete elimination of the heat load at $20 \mathrm{~K}$ is currently impractical due to the limitations in lift available on flight cryocoolers. In order to reduce the heat load, without having to remove heat at $20 \mathrm{~K}$, the concept of Reduced Boil-Off uses cooled shields within the insulation system at approximately $90 \mathrm{~K}$. The development of Load-Bearing Multilayer Insulation (LB-MLI) allowed the $90 \mathrm{~K}$ shield with tubing and cryocooler attachments to be suspended within the MLI and still be structurally stable. Coupon testing, both thermal and structural was performed to verify that the LB-MLI should work at the tank applied level. Then tank applied thermal and structural (acoustic) testing was performed to demonstrate the functionality of the LB-MLI as a structural insulation system. The LB-MLI showed no degradation of thermal performance due to the acoustic testing and showed excellent thermal performance when integrated with a $90 \mathrm{~K}$ class cryocooler on a liquid hydrogen tank.
\end{abstract}

\section{Introduction}

T ONG duration storage of cryogenic propellants has long been a goal of the space exploration and operations Lcommunities. Proposals for both demonstrations and operational vehicles using cryogenic propellants that require storage between several days and several years have been made since the early 1970s. The core issue with long duration storage of propellant is minimizing (or eliminating) the heat load into the tank so that as much of the propellant as possible is available to use. The two main classes of heat load into a tank are through the structure (including fluid lines) and through the acreage of the tank. While thermal insulation systems such as MLI work to minimize the environmental heat load reaching the propellants through the acreage of the tanks, further improvements can be had by introducing mechanical refrigeration systems. Using gas flow to intercept heat within an insulation system has been done on a multitude of science missions where the useful life of the instrument was driven by the life of the cryogenic dewar. ${ }^{1,2}$ Such systems, also known as vapor cooled shields (essentially gas tubes on a shield surrounding the tank) have been demonstrated on small dewars where the shields can be suspended from

\footnotetext{
${ }^{1}$ Cryogenic Engineer, Fluid System and Cryogenic Branch, M/S: 301-3, AIAA Senior Member.

${ }^{2}$ Aerospace Engineer, Propulsion Research and Technology Applications Branch, M/S: ER-24, AIAA Member.

${ }^{3}$ Researcher, Cryogenics Laboratory, M/S: 244-10.

${ }^{4}$ Researcher, Propulsion and Propellants Branch, M/S: 301-3, AIAA Member.
}

American Institute of Aeronautics and Astronautics 
the structural members of the tank. A similar closed loop system can be developed by replacing the evaporating vapor flow with a force convection loop serviced by a cryocooler or refrigeration system. This system can be attached both within the insulation system and to the structural support system, reducing the heat load in both locations. The relative importance of the structural and acreage heat loads depend on the design, and based off of known goals, the cooling can be applied in the location where it improves the thermal performance the most.

Large propulsion systems will not have the luxury of suspending such a shield off of the tank structural members as launch vibrations will cause the tubes to impact the tank wall. As such, some structural mechanism is needed to support the shields off of the tank wall. The Space Shuttle Power Reactant Storage \& Distribution system (PSRD) supercritical hydrogen tanks that provided power and water to the Space Shuttle used plastic stand-offs to support their thermal shields off of the tank wall. ${ }^{3}$ This provides a basis for beginning the design process however, the PSRD systems used a fairly thick wall shield as opposed to a sheet of aluminum foil.

\section{A. Reduced Boil-off Concept}

Between 2004 and 2006, NASA's In-Space Cryogenic Propellant Depot (ISCPD) Project investigated the various ways of integrating cryocoolers with cryogenic propellant storage tanks. The goal was to dramatically decrease or even eliminate boil-off losses while staying within acceptable mass and power requirements. For liquid oxygen (LO2) storage, this can be done using flight heritage technology: It is possible to integrate existing high capacity 90 $\mathrm{K}$ flight coolers, or scaled-up versions of them, directly with an LO2 tank. The same approach has not yet been shown viable for liquid hydrogen (LH2) storage as high capacity $20 \mathrm{~K}$ flight coolers do not yet exist. However, the early analysis and modeling ${ }^{4}$ predicted that a large fraction of the heat leak to an LH2 tank could be intercepted at around $90 \mathrm{~K}$, thus largely circumventing the need for a $20 \mathrm{~K}$ cooler. For intercepting MLI heat leak, the broad area cooling (BAC) concept was proposed, whereby a cooler is integrated with a pressurized gas circulation network, which in turn removes heat from a large surface area, but low mass, thermal radiation shield embedded within the MLI.

To flush out this concept, NASA funded, in addition to ongoing analytical and modeling work, a series of benchtop experiments ${ }^{5}$ at NASA Ames Research Center, which addressed questions of thermal stability, heat transfer effectiveness, and temperature uniformity in BAC systems. Finally, NASA partnered with Ball Aerospace Technologies Corporation (BATC) to demonstrate a Cryogenic Boil-off Reduction System (CBRS) consisting of a 500 liter liquid nitrogen tank, an MLI-embedded aluminum foil BAC shield and a flight-like cryocooler with integral helium circulator. ${ }^{6}$ As a result of removing heat from both the shield and tank support structure, the tank heat load was reduced by over $82 \%$.

To compliment these small-scale thermal tests, a number of structural tests were performed at NASA MSFC and GRC, wherein MLI-embedded BAC panels were subjected to rapid depressurization and vibro-acoustic loads in order approximated the launch environment. ${ }^{7,8}$ The test results were encouraging.

In an effort to test such a system for large scale tanks, the Cryogenic Propellant Storage and Transfer (CPST)

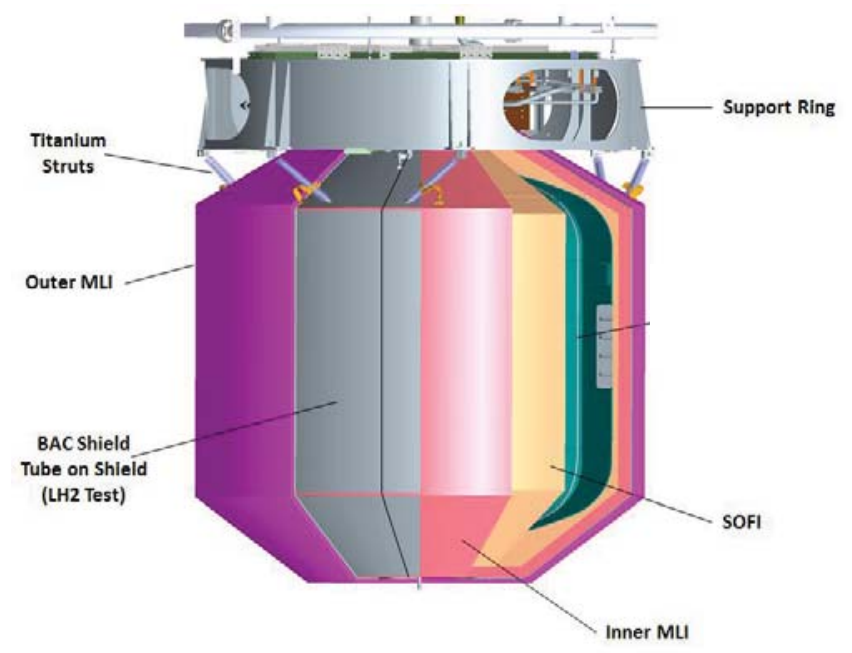

Figure 1. Tank Applied Insulation System.
Technology Demonstration Mission developed a CBRS test article for testing such a cooling loop and broad area cooled shield both thermally and structurally (acoustically). The project first tested a system that used a system of plastic stand-offs directly mounted to the tank wall, similar to the PSRD solution. ${ }^{9}$ Due to concern that the system of plastic stand-offs would greatly increase the heat load onto the tank, a structural insulation task was initiated in concert with the Game-Changing Technology Program.

The basis for the structural insulation system was the Integrated Multilayer Insulation (IMLI) and Load-Responsive Multilayer Insulation (LRMLI) developed by Quest Thermal Group and Ball Aerospace and Technology Corporation in cooperation with NASA. ${ }^{10}$ This new insulation called Load-Bearing Multilayer Insulation (LBMLI) uses discrete spacers between each layer to 
increase the conduction length and subsequent thermal resistance between the tank and the shield. The refrigeration shield was mounted using epoxied velcro to the LB-MLI, which was mounted onto Spray on Foam Insulation (SOFI) that was sprayed onto the tank using epoxied velcro.

\section{Tank Applied Insulation Systems}

In order to demostrate that the new insulation was appropriate for use as a high performance, structural insulation system, the Load-Bearing MLI was applied to a pair of 1.2 meter diameter by 1.4 meter long tanks for thermal and acoustic testing as shown in Figure 1. Both tank systems were as identical as possible for the thermal and acoustic testing. The stainless steel tank was covered with a minimum of half of an inch of spray on foam insulation (SOFI), which was not contoured to the tank, but was in a truncated cone geometry that allowed for easier MLI fabrication and installation. The LB-MLI was then applied on top of the shaped foam. A broad area cooling (BAC) shield, which contained tubing to be integrated into a cryocooler placed on top of the LB-MLI and a traditional MLI blanket was placed on top of the BAC shield.

\section{A. Spray on Foam Insulation (SOFI)}

The SOFI was applied to the tank with the dimensions shown in Figure 2. The conic domes were chosen instead of conformal domes in an attempt to simplify MLI construction and integration especially around the penetrations (such as fill and vent line) on the top of the tank.

The SOFI is the third generation foam developed by Marshall Space Flight Center (MSFC), commonly known as S-180. ${ }^{11}$ The minimum thickness on the side of the tank wall was sized to prevent nitrogen liquefaction during possible atmospheric pressure $(760$ Torr, $101.3 \mathrm{kPa})$ testing to simulate ground hold. This calculation was completed by comparing the thermal resistances of the SOFI and MLI insulations such that the interface temperatures was greater than $95 \mathrm{~K}$. Using a thermal conductivity of $0.012 \mathrm{~W} / \mathrm{m} / \mathrm{K}$ for the SOFI and $0.025 \mathrm{~W} / \mathrm{m} / \mathrm{K}$ for the MLI (essentially quiescent nitrogen gas), a required thickness of a quarter of an inch was calculated.

The top and bottoms were designed to cover the flanges on the various penetrations for simplification of MLI installation. At some locations, the thickness was up to $10 \mathrm{~mm}$ (4 inches) thick.

\section{B. Inner Multilayer Insulation}

The inner MLI system was designed by Quest Thermal Group and Ball Aerospace to take the place of the traditional inner MLI blanket and tubing supports from the earlier Reduced Boil-off Test. ${ }^{12}$ The two driving requirements were the reuse of the existing hardware from the previous testing and supporting the Broad Area Cooling (BAC) shield off of the blankets to cut any thermal shorts between the shield and the tank wall. The cross section of the insulation system is shown in Figure 3.

The inner MLI system was made out of Load Bearing Multilayer Insulation (LBMLI), which is a part of the IMLI/LR-MLI family of insulation systems. The IMLI

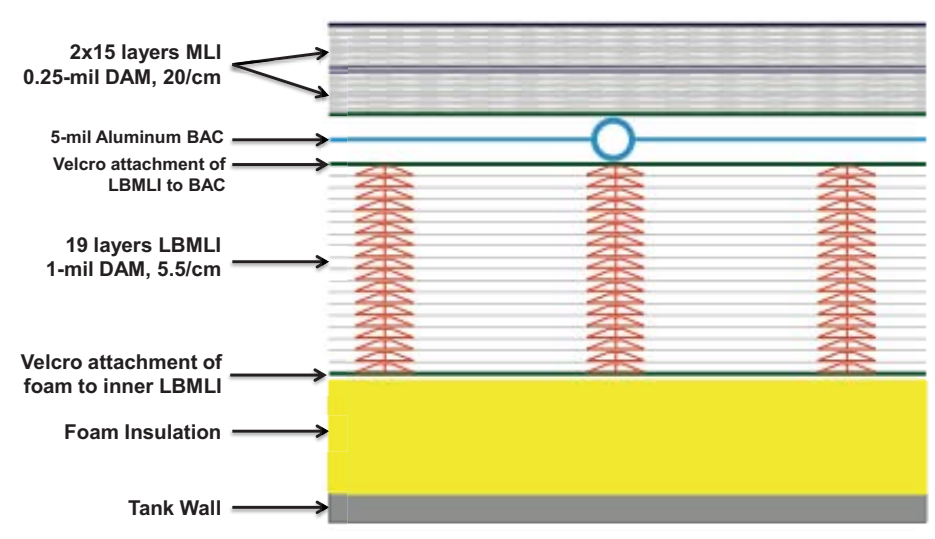

Figure 3. Cross section of Insulation System. 
family of insulation systems uses discrete spacers that are fixed to the reflectors on either side of it. In order to use the same BAC shield, the LB-MLI was designed with a thickness of $33.6 \mathrm{~mm}$ (1.3 inches). The inner contour of the blanket matched the SOFI shell and the thickness of the blanket was uniform. Holes were cut in the blanket for each of the penetrations.

The blanket was designed to support the mass of the BAC and the outer MLI blanket through prescribed dynamic/acoustic loads. Coupon random vibration testing was performed by Quest Thermal Group with a dummy load to demonstrate that the blanket would survive up to approximately $10 \mathrm{G}_{\mathrm{RMS}}$. The blanket was also designed to survive rapid evacuations similar to what might be seen during the launch and ascent phases of a mission. In order to facilitate the rapid evacuation, $6 \mathrm{~mm}(0.25 \mathrm{inch})$ perforations totaling an open area of $0.01 \%$ were regularly spaced within the blanket. ${ }^{12}$

The Inner MLI blanket was attached to the SOFI and to the BAC shield via epoxied velcro strips. Thus the load path supporting the BAC shield and outer MLI went to the tank through the Velcro attachments on the BAC shield, the LB-MLI, the Velcro attachments to the SOFI, the SOFI, and finally to the tank wall.

\section{Broad Area Cooled Shield and Outer Multilayer Insulation}

The BAC shield was designed to be integrated with the reverse turbo Brayton cycle cryocooler. ${ }^{9}$ The mass of the BAC shield was approximately $8.6 \mathrm{~kg}(19 \mathrm{lbm})$, most of which was due to the $6 \mathrm{~mm}(0.25 \mathrm{inch})$ stainless steel tubing. The tubing was attached to a thin aluminum shield ( 5 mil) that was perforated for evacuation.

The outer MLI blanket was used to lower the heat load onto the $90 \mathrm{~K}$ shield. It was made of 30 layers of traditional MLI consisting of double aluminized mylar with Dacron netting spacers between each layer. The outer blanket was split into two sub-blankets of 15 layers each, with a nominal layer density of 2 layers $/ \mathrm{mm}$. The mass of the outer blanket was approximately $7 \mathrm{~kg}$.

\section{Structural, Fluid, and Instrumentation Penetrations}

For both thermal and acoustic testing, the tank was suspended below a support ring by six titanium-aluminumvanadium alloy struts ( $\mathrm{Ti} 6 \mathrm{Al} 4 \mathrm{~V}$ ). Thin wall tubes served as the fill line and vent line for the tank. These supports and fluid lines are not flight like, but were designed to maximize the percentage of heat load going through the insulation system for a more accurate understanding of those components. A silicone diode temperature rake was inserted through another tank penetrations. All support and penetration heat loads were measured by placing two silicon diodes in the conduction path. Additionally, the BAC shield was strapped to all struts and penetrations using copper straps to lower the conduction heat load into the tank (and reject it to the cryocooler) for thermal testing .

\section{Acoustic Testing}

In order to demonstrate that the insulation system could survive launch acoustic environments, test coupons and the tank applied LB-MLI were subjected to a flight protoqualification acoustic environment in the reverberant acoustic test chamber at Marshall Space Flight Center (MSFC). ${ }^{13}$ The acoustic environment used for all test series is the worst-case protoqualification environment tailored to envelope all candidate launch vehicles for the CPST flight article. The test consists of a 1 minute, Maximum Expected Flight Level (MEFL) of $135+3 \mathrm{db}$ per NASA-STD-7001A, as shown in Figure 4. All testing was done at ambient temperature, no cooling or heating was applied.

Testing was first done at the coupon level to give confidence in the structural design of the LBMLI system. Following successful coupon testing, tank applied testing

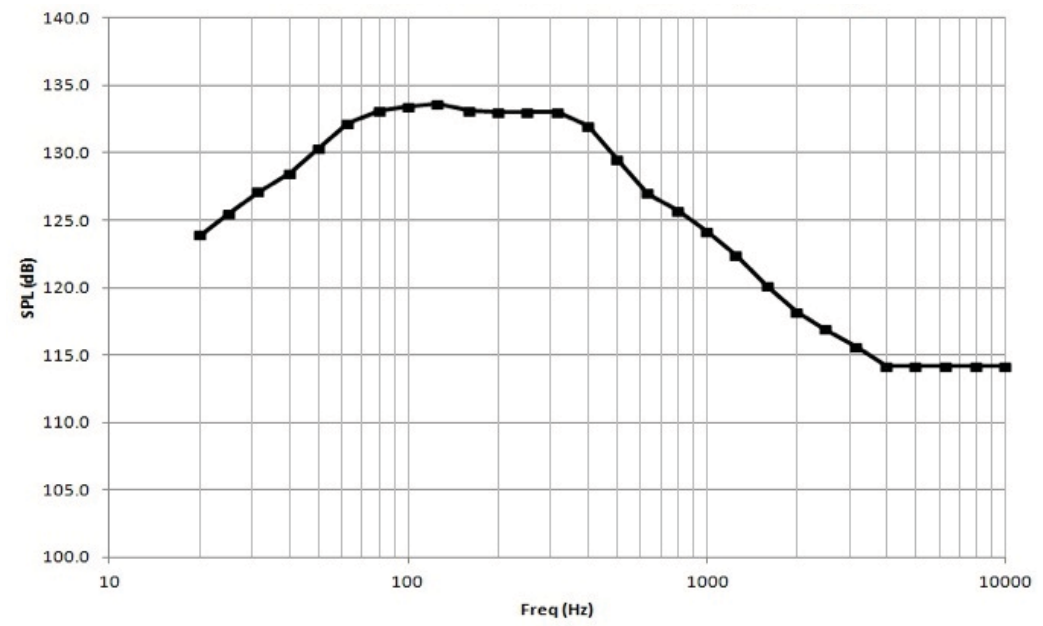

Figure 4. Protoqualification Acoustic Environment. 
was conducted. In order to shown any thermal degradation to the system, liquid nitrogen boil-off testing was conducted both prior to and after the acoustic testing. However, the acoustic testing was run at ambient temperature.


Figure 5. Curved panel and flat plate coupons in the acoustic chamber.

\section{A. Coupon Testing}

Two test coupons were used for acoustic testing. The first is a $0.9 \mathrm{~m}$ ( 3 foot) square flat test coupon with 19 layers of LB-MLI attached to SOFI simulant via Velcro with no BAC shield simulate attached. The second is a $0.9 \mathrm{~m} \mathrm{x} 1.5 \mathrm{~m}$ ( 3 foot $\times 5$ foot) curved panel to mimic the curvature of the a tank cylinder. The curved panel coupon consists of 19 layers of LB-MLI, a BAC simulant attached to the LB-MLI via Velcro tabs, and a 30 layer traditional MLI blanket simulant attached to the outer frame of the test coupon. Accelerometers were placed on the coupon frame and on the BAC shield simulant to capture acceleration responses. Three microphones were used in the reverberating chamber to capture sound pressure data. Both coupons were subjected to the same MEFL levels as the tank applied system. These are shown in Figure 5.

\section{B. Tank Applied Testing}

The Vibro Acoustic Test Article (VATA) was used to conduct the vibro acoustic tank applied tests. The VATA test article was constructed to be nearly identical to the Reduced Boil-Off (RBO) test article sent to GRC for liquid hydrogen thermal testing, the main differences were in the final contour of the SOFI as the hand trim was slightly different on the two different test articles. 19 layers of LB-MLI was installed as the inner insulation blanket followed by a BAC shield and a 30 layer tank applied traditional MLI blanket. The LB-MLI was assembled and installed on to the VATA tank by Quest Thermal Group. The BAC shield, 30 layer

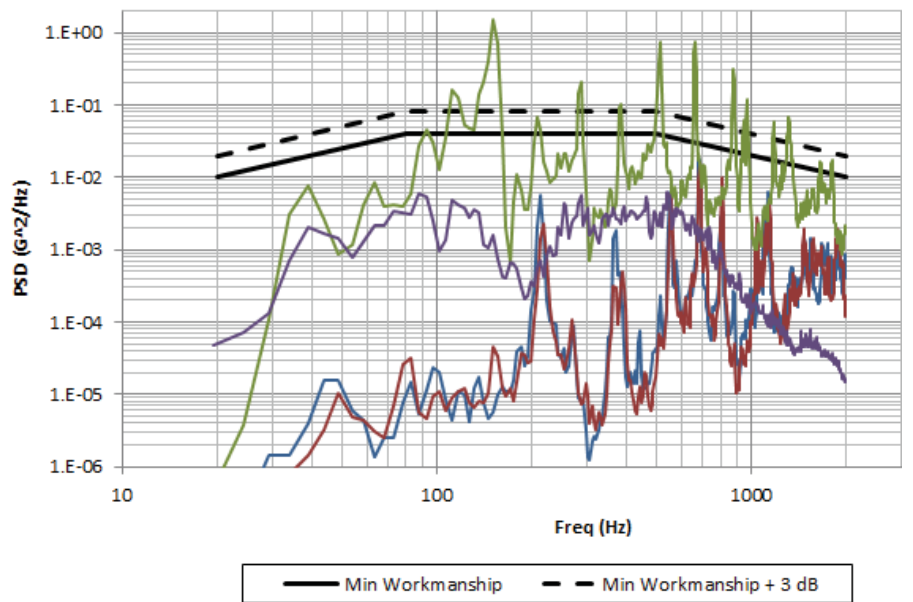

(a)



(b)

Figure 6. LB-MLI Coupon acoustic response for the (a) flat panel and (b) curved panel sections compared to the Workmanship lines which define the minimum inputs. 


\begin{tabular}{|c|c|c|}
\hline Accel \# & Description & Type \\
\hline 1 & On gusset, near strut attach point & Triax \\
\hline 2 & On tank, near strut attach point & Triax \\
\hline 3 & On support column, top surface & Triax \\
\hline 4 & On tank surface, mid-barrel section & Uniaxial \\
\hline 5 & Same as \#4, clocked 120 degrees around tank & Uniaxial \\
\hline 7 & On top of tank & Uniaxial \\
\hline 8 & On bottom of tank & Uniaxial \\
\hline 9 & On gusset, near strut attach point & Triax \\
\hline 10 & On tank, near strut attach point & Triax \\
\hline
\end{tabular}

(a)

(b)

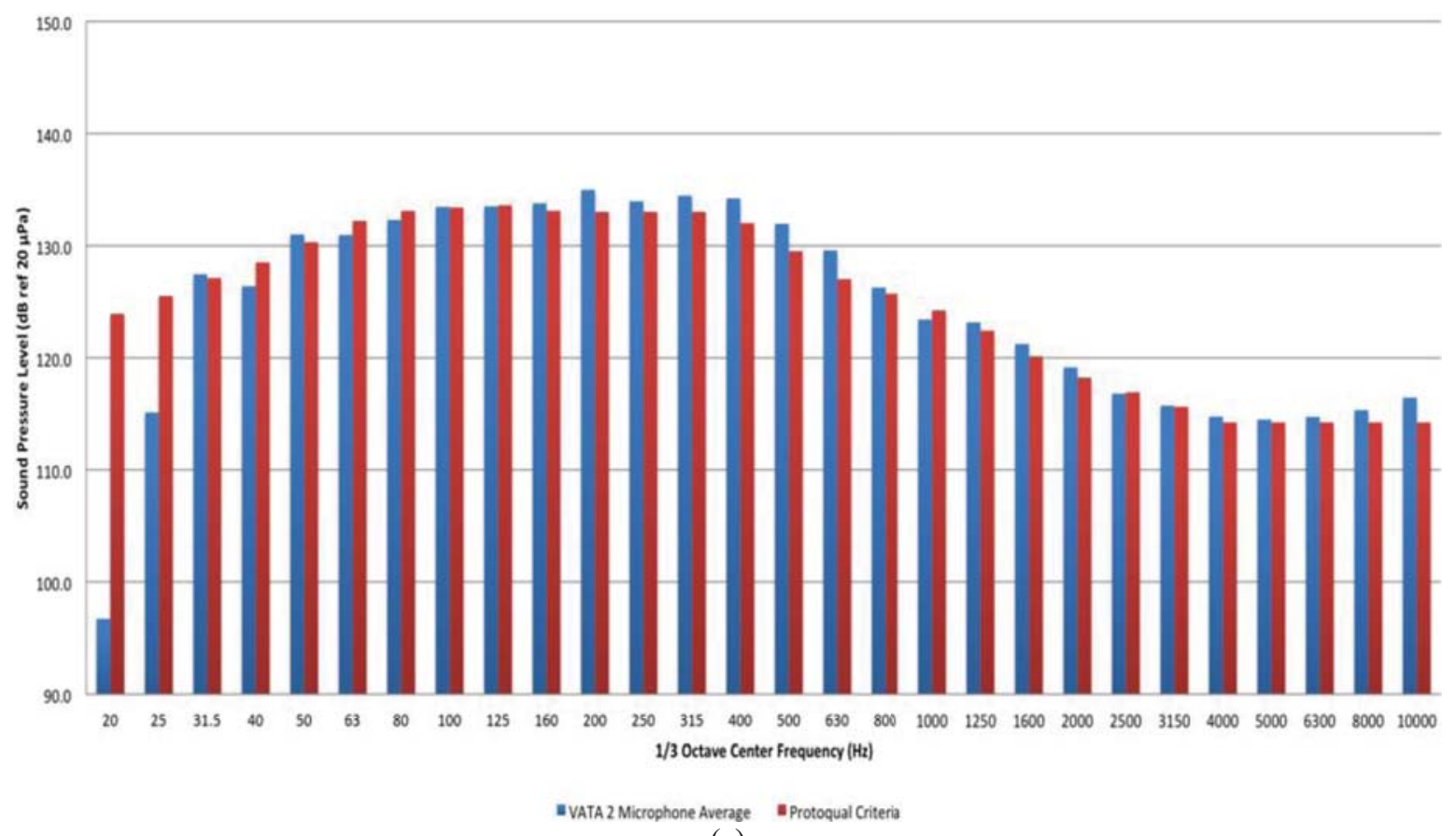

(c)

Figure 7. Accelerometer test set up and results: (a)accelerometer type and location, (b) pictoral location, and (c) as-tested sound pressure level vs. target sound pressure level.

outer blanket and test tank were reused from a previous tank applied vibro-acoustic test. Microphones were placed around the reverberating chamber and accelerometers were glued onto the tank surface, structural support legs, and the BAC shield at locations shown in Figure 7.

\section{Acoustic Testing Results}

Results for the flat and curved panel coupons are showed in Figure 6. Both figures depict the complete set of responses relative to the minimum workmanship level and minimum workmanship level $+3 \mathrm{db}$. The minimum workmanship level was the current prescribed protoqualification random vibrations input levels for components within the CPST flight article. Figure 7 shows that the acoustic energy input was appropriate (i.e. it met the minimum workmanship $+3 \mathrm{db}$ requirement) for all frequencies above $31 \mathrm{~Hz}$.

Results show the flat test coupon with the exposed "LB-MLI only" showed minimal dynamic responsiveness because it was rigid enough to suppress the acoustic input. Flat panel coupon testing shows LB-MLI, on its own, is structurally sound in an acoustic environment. Curved panel results show the test coupon is most responsive in the 250-400 Hz range due to the acoustic input peaking during the same frequency range. The highest response, 10.39 $\mathrm{G}_{\mathrm{RMS}}$, was located on the center of the curved panels back face. All other responses fall short of the min workmanship response levels. Post test visual inspection showed no physical damage to the LB-MLI nor its supporting features (BAC shield simulant and 30 layer traditional MLI simulant). This indicates that LB-MLI is structurally sound with the BAC shield simulator in-place resting on it. The success of both the flat and curved panels in the acoustic environment suggested that the system should procede on to tank applied testing. 
Microphone data in Figure 7 shows that generally the as tested environments were slightly greater than the target protoqual criteria. Due to its small size, the reverberating chamber could not produce adequate sound pressure levels in the low frequency range, below $50 \mathrm{~Hz}$. Regardless the test was able to produce the target spectrum with reasonable accuracy.

Tank applied LB-MLI acoustic test results are shown in Figure 8 as corresponding acceleration maximum response data recorded. Results show similar trends to the LB-MLI coupon tests with little response at the lower frequency spectrum. The highest acceleration response of $8.7 \mathrm{G}_{\mathrm{RMS}}$ was recorded on the self-supported BAC shield along the tanks equator. Pre-test predictions stated a response above $6 \mathrm{G}_{\mathrm{RMS}}$ would show a cause for concern on the test article. Although the actual data exceded $6 \mathrm{G}_{\mathrm{RMS}}$, post test visual inspection of the insulation system showed no physical damage to the BAC shield nor the LB-MLI blankets. With the improved understanding of the system, the criteria was changed to $10 \mathrm{G}_{\mathrm{RMS}}$.

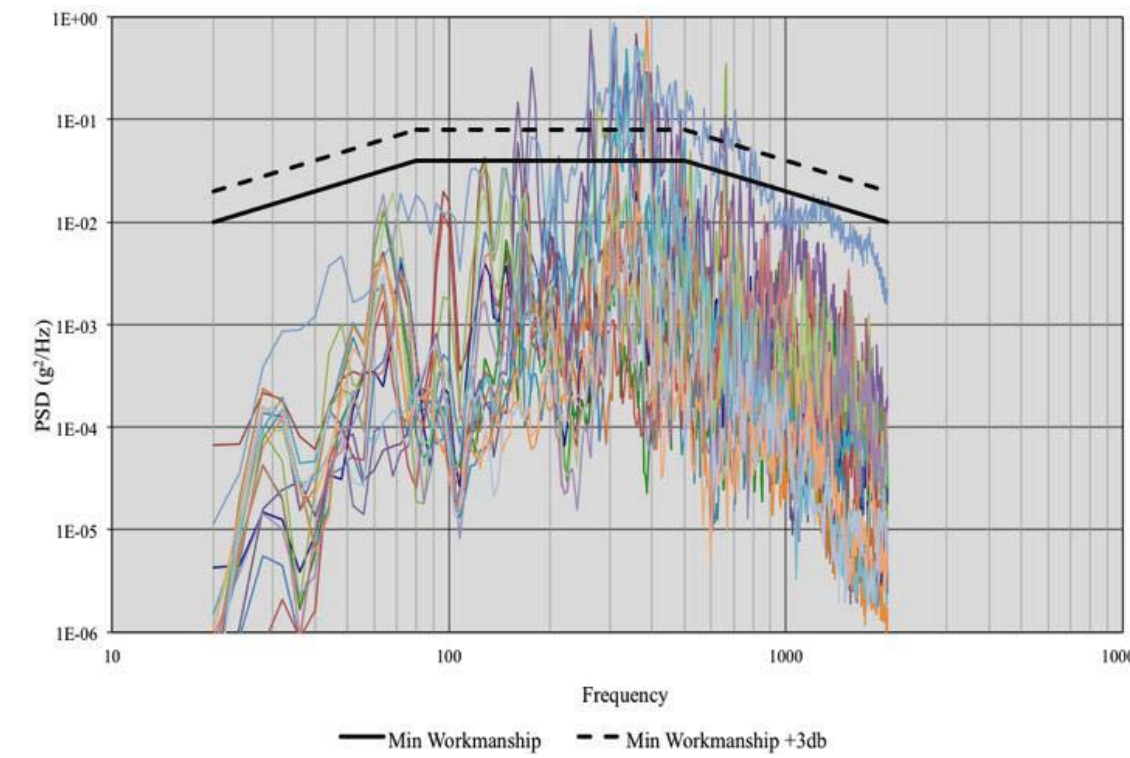

\begin{tabular}{|c|c|}
\hline \multicolumn{2}{|c|}{ VATA 2 Full Scale Tank Test } \\
\hline Accelerometer & GRMS \\
\hline R1R & 1.498 \\
\hline R1L & 1.551 \\
\hline R1T & 0.867 \\
\hline R2R & 4.709 \\
\hline R2L & 1.31 \\
\hline R2T & 0.728 \\
\hline R3R & 1.24 \\
\hline R3L & 1.089 \\
\hline R3T & 2.982 \\
\hline R4R & 6.407 \\
\hline R5R & 3.041 \\
\hline R7L & 3.061 \\
\hline R8L & 8.697 \\
\hline R9R & 2.051 \\
\hline R9L & 1.576 \\
\hline R9T & 0.991 \\
\hline R10R & 5.22 \\
\hline R10L & 1.046 \\
\hline R10T & 0.769 \\
\hline
\end{tabular}

Figure 8. VATA tank applied test frequency acceleration response.

Liquid nitrogen boil-off testing was performed both prior to and after the acoustic testing (but before the physical inspection). The thermal testing was an additional method (other than physical inspection) to check for any damage or degradation post acoustic testing. There was no change in the boil-off rate measured in the pre and post acoustic liquid nitrogen thermal tests showed no performance difference from the pre-acoustic thermal test. This indicates that with a reasonable degree of confidence, a tank applied LB-MLI system can survive a fairing enclosed launch environment with minimal thermal performance impacts.

\section{Thermal Testing}

Thermal testing of the LB-MLI was completed on both the coupon and tank levels. Coupon testing was performed both between $20 \mathrm{~K}$ and $90 \mathrm{~K}$ and between $77 \mathrm{~K}$ and $293 \mathrm{~K}$. Tank applied testing was completed using liquid hydrogen.

\section{A. Coupon Testing}

Small calorimeter testing provides rapid results from variation of parameters that can be incorporated in the design of tank applied blanket systems. Coupon testing was performed to determine the baseline MLI blanket heat leak and to help understand the performance dependence on number of layers and varying warm boundary temperature. Due to the restrictions in place of testing the same inner MLI blanket thickness as had been performed on the first Reduced Boil-off test, it was of interest to investigate the effect of different layers between the somewhat unique boundary temperatures of $20 \mathrm{~K}$ and $90 \mathrm{~K}$, the inner MLI boundary temperatures under the BAC shield. Since a majority of insulation system testing is carried out using liquid nitrogen, it was desirable to get test data between $77 \mathrm{~K}$ and room temperature $(\sim 293 \mathrm{~K})$ for the creation and augmentation of existing models. Additional 
testing was carried out to quantify the impact of seams and perforations within the LB-MLI design. The test matrix for the coupon testing is shown in Table 1.

Thermal coupons of the Load Bearing Multilayer Insulation were provided by Quest Thermal group for testing at Kennedy Space Center (KSC) and Florida State University (FSU). At FSU, testing was performed on both 5 and 10 layer LB-MLI blankets between $20 \mathrm{~K}$ and $90 \mathrm{~K}$ on the Multilayer Insulation Calorimetry Experiment (MIKE). The results of the FSU testing are thoroughly described by Hurd. ${ }^{14}$ At KSC, testing was performed between $77 \mathrm{~K}$ and various warm boundary temperatures between $293 \mathrm{~K}$ and $325 \mathrm{~K}$ on Cryostat-100. ${ }^{15}$ Testing showed that there was no additional penalty due to the seaming methods used in LB-MLI and that the thermal penalties due to perforations were also small enough to ignore.

Table 1. Calorimeter Test Matrix.

\begin{tabular}{cccccc}
\hline $\begin{array}{c}\text { C-100 coupon } \\
\text { name }\end{array}$ & $\begin{array}{c}\text { Number of } \\
\text { Layers }\end{array}$ & Perforated & $\begin{array}{c}\text { Number of } \\
\text { Seams }\end{array}$ & Calorimeter & $\begin{array}{c}\text { Warm Boundary } \\
\text { Temperatures (K) }\end{array}$ \\
\hline A & 5 & No & 1 & C-100 and MIKE & $293,316,325,90$ \\
B & 10 & No & 1 & C-100 and MIKE & $293,305,325,90$ \\
C & 10 & Yes & 1 & C-100 only & 293,325 \\
E & 10 & No & 2 & C-100 only & 293,325 \\
D & 20 & No & 1 & C-100 only & $293,305,325$ \\
\hline
\end{tabular}

\section{B. Tank Applied Testing}

Tank applied thermal testing was conducted to demonstrate the thermal performance of the integrated BAC and LB-MLI system. The insulated liquid hydrogen tank was lowered into a thermal vacuum chamber with a cold wall that is painted black to simulate deep space. The cold wall temperatures were controlled to $220 \mathrm{~K}$ for the majority of the test matrix with a final test with the wall temperature set at $300 \mathrm{~K}$. Testing was completed with the BAC shield off and set to both $80 \mathrm{~K}$ and $90 \mathrm{~K}$ control points. Due to issues with previous testing, the passive and $90 \mathrm{~K}$ control points were conducted both with and without a bypass valve open to mitigate (and quantify) the effects of thermoacoustic oscillations on the previous testing. Testing at the $80 \mathrm{~K}$ set point was conducted with the tank at both $90 \%$ full and $25 \%$ full to help understand the effects of fill level on the broad area cooling system. For the rest of the testing, the liquid hydrogen fill level was maintained at approximately $90 \%$ full or higher for the duration of the test. The tank pressure was maintained at 25 psia for the duration of the testing. Test 7 was a series of tests of rapid evacuation of the insulation system simulating the launch and ascent phases of a mission that the system may see. The full test matrix is shown in Table 2.

Table 2. LB-MLI Test Matrix

\begin{tabular}{|llllll|}
$\begin{array}{l}\text { Test } \\
\#\end{array}$ & $\begin{array}{l}\text { BAC } \\
\text { Set Point (K) }\end{array}$ & $\begin{array}{l}\text { Bypass Valve } \\
\text { (open/closed) }\end{array}$ & Fill Level (\%) & $\begin{array}{l}\text { Environmental } \\
\text { Temperature (K) }\end{array}$ & Test Type \\
\hline $\mathbf{1}$ & $80 \mathrm{~K}$ & Open & 90 & 220 & Steady State \\
\hline $\mathbf{2}$ & $80 \mathrm{~K}$ & Open & 25 & 220 & Steady State \\
\hline $\mathbf{3}$ & N/A & Open & 90 & 220 & Steady State \\
\hline $\mathbf{4}$ & N/A & Closed & 90 & 220 & Steady State \\
\hline $\mathbf{5}$ & $90 \mathrm{~K}$ & Open & 90 & 220 & Steady State \\
\hline $\mathbf{6}$ & $90 \mathrm{~K}$ & Closed & 90 & 220 & Steady State \\
\hline $\mathbf{7}$ & N/A & Open & 90 & 300 & Rapid Evacuation \\
\hline $\mathbf{8}$ & N/A & Open & 90 & 300 & Steady State \\
\hline
\end{tabular}

A broad overview of the testing and rapid depressurization are presented elsewhere ${ }^{9,16}$, so this paper focuses solely on the results of tests $1,2,3,5$, and 8 on the LB-MLI blanket.

\section{Test Results}

The results from the coupon testing were compared to layer-by-layer models of insulation performance. The models compared very well for the liquid nitrogen based testing and were within $5 \%$ of the model predictions. However, the data from the $20 \mathrm{~K}$ to $90 \mathrm{~K}$ testing did not compare well with the model, showing errors of nearly $100 \%$.

A summary of the results from tests 1, 2, 3, 5, and 8 on the inner LB-MLI blanket are shown in Table 3 . The conduction heat loads include the structural support of the tank, which consisted of six titanium struts, the fill line, 
the vent line, instrumentation wires, an instrumentation feedthrough port, and the internal silicone diode rake that was used to determine liquid hydrogen fill level. The MLI penetration heat loads are calculated based on previous work in determining the degradation of MLI around penetrations. ${ }^{17}$ A $12 \mathrm{~mm}$ cryolite blanket sock was used around each penetration. The mean surface area of the inner MLI blanket was $7.04 \mathrm{~m}^{2}$ - the square root of the product of the foam surface area $\left(6.81 \mathrm{~m}^{2}\right)$ and the shield surface area $\left(7.27 \mathrm{~m}^{2}\right)$.

For Test numbers $1 \& 2$, the heat leak from the BAC shield running at approximately $80 \mathrm{~K}$ to the liquid hydrogen tank was $1.67 \& 1.68 \mathrm{~W}$ respectively. After the conduction heat loads were accounted for, the remaining $0.72 \mathrm{~W}$ was assumed to come from the MLI. Of the $0.72 \mathrm{~W}, 0.17$ was calculated to be due to the integration of the penetrations to the tank insulation. This left $0.55 \mathrm{~W}$ coming through the insulation, or a heat flux of $0.078 \mathrm{~W} / \mathrm{m}^{2}$. While this is not out of line with historical data, it is not on par with the best results that have been performed on tank calorimeters. Additionally, the heat flux is approximately 4 times greater then the model that was developed during calorimeter testing predicted.

Test 5 was run with the BAC shield cooled to $90 \mathrm{~K}$ and the heat load to the tank was $1.83 \mathrm{~W}$. After the conduction heat loads were accounted for, the remaining $0.82 \mathrm{~W}$ was assumed to come from the MLI, of which 0.17 $\mathrm{W}$ was estimated through the penetrations. The remaining $0.64 \mathrm{~W}$ coming through the insulation would result in a heat flux of $0.092 \mathrm{~W} / \mathrm{m}^{2}$. Again, this is not out of line with historical calorimeter data but is much higher than the predicted heat flux. In changing the temperature from $80 \mathrm{~K}$ to $90 \mathrm{~K}$ on the shield, the heat flux increased by just over $18 \%$. This would indicated the heat flux was a function of roughly $\mathrm{T}_{\mathrm{h}}^{1.5}$.

Table 3. Summary of Inner MLI Blanket Test Data from LB-MLI Testing.

\begin{tabular}{|c|c|c|c|c|c|c|c|}
\hline Test \# & $\begin{array}{ll}\text { Heat } & \text { Load } \\
\text { to } & \text { Tank } \\
\text { (W) } & \end{array}$ & $\begin{array}{l}\text { Conduction } \\
\text { Heat Loads } \\
\text { (W) }\end{array}$ & $\begin{array}{l}\text { Net } \\
\text { Remainder } \\
\text { (W) }\end{array}$ & $\begin{array}{l}\text { MLI } \\
\text { Penetrations } \\
\text { (W) }\end{array}$ & $\begin{array}{l}\text { MLI Heat } \\
\text { Load (W) }\end{array}$ & $\begin{array}{l}\text { MLI } \\
\text { Heat } \\
\text { Flux } \\
\left(\mathbf{m W} / \mathbf{m}^{2}\right)\end{array}$ & $\begin{array}{l}\text { Predicted } \\
\text { MLI Heat } \\
\text { Flux (mW/m²) }\end{array}$ \\
\hline 1 & 1.67 & 0.94 & 0.73 & 0.17 & 0.56 & 79 & 19 \\
\hline 2 & 1.68 & 0.97 & 0.71 & 0.17 & 0.54 & 76 & 17 \\
\hline 3 & 3.32 & 1.69 & 1.63 & 0.17 & 1.46 & 207 & 116 \\
\hline 5 & 1.83 & 1.01 & 0.82 & 0.17 & 0.64 & 92 & 21 \\
\hline 8 & 6.12 & 2.77 & 3.35 & 0.28 & 3.07 & 436 & 310 \\
\hline
\end{tabular}

Test 3 was run with the cryocooler off and based on the relative thermal resistances of the inner and outer MLI blankets and an environmental temperature of $220 \mathrm{~K}$, the BAC shield floated to $182 \mathrm{~K}$. The total heat load to the tank was $3.32 \mathrm{~W}$, of which $1.69 \mathrm{~W}$ was through the conductive members and 1.63 W was through the LB-MLI. Thus the resultant heat flux was $0.21 \mathrm{~W} / \mathrm{m}^{2}$. Similarly Test 8 was run at an environmental temperature of $300 \mathrm{~K}$ and the BAC shield floated to $253 \mathrm{~K}$. The total heat load to the tank was $6.12 \mathrm{~W}$, of which $2.77 \mathrm{~W}$ was through conductive members and $0.28 \mathrm{~W}$ was attributed to the penetrations in the MLI, resulting in a heat flux of $0.31 \mathrm{~W} / \mathrm{m}^{2}$ through the LB-MLI.

\section{Further LB-MLI Data Analysis and Model Refinement}

The tank-applied LB-MLI heat leak numbers listed in Table 3 were calculated by assuming a thermal balance of all known heat leaks on the tank, e.g., strut and plumbing heat leaks. It is clear that a small (relative to the total tank heat load) unaccounted heat leak, or error in the measurement or calculation of the known heat leaks, would result in a substantially different estimate of the blanket's thermal performance, perhaps yielding a better correspondence with model predictions. In order to investigate this possibility, a more detailed thermal analysis of the LB-MLI was performed, taking advantage of the measured temperature profiles (Figure 9). There were four such profiles: one each on the top and bottom truncated conical sections, and two at the equator of the cylindrical section.

Two sets of calculations were performed:

(1) The heat leak through the blanket was estimated, to within an unknown scale factor, for the cooler-off and both cooler-on states. Taking the cooler-on/off ratio cancels the unknown scale factor and allows for the calculation of the unaccounted heat leak. This turns out to be $0.3 \mathrm{~W}$, which is refined down to $0.26 \mathrm{~W}$ in the second calculation.

(2) Layer-to-layer heat transfer relations were used to curve-fit the LB-MLI temperature profiles. The curvature of the profile can be taken as an indication of the relative magnitude of conduction and radiation contributions to the heat leak.

Throughout these calculations the assumption is made that the heat flux $q$ through the blanket is via two independent paths: spacer conduction $q_{C}$ and layer-to-layer thermal radiation $q_{R}$. The conduction term depends on 
the boundary temperatures, the temperature-dependent thermal conductivity of the spacer material, and the spacer dimensions. The radiation term depends on the boundary temperatures and the temperature-dependent emissivity $\varepsilon(T)$ of the reflective layers. The traditional way of describing the tank-applied heat leak is to multiply the sum of these two terms (plus a residual gas conduction term, if it is thought to be significant) by a constant scale factor $(S F): q=S F^{*}\left(q_{C}+q_{R}\right)$. The scale factor is meant to quantify any performance-degrading imperfections in the blanket that have not been otherwise explicitly accounted for. Ideally $S F=1$, or $q_{\text {ideal }}=q_{C}+q_{R}$, which should apply to the coupon measurements. As noted above, the conduction and radiation models developed for LB-MLI describe the $90-300 \mathrm{~K}$ coupon measurements reasonably well, but are off by a factor of $\sim 2$ when applied to the $20-90 \mathrm{~K}$ data. A similar discrepancy is seen in the tank-applied data.

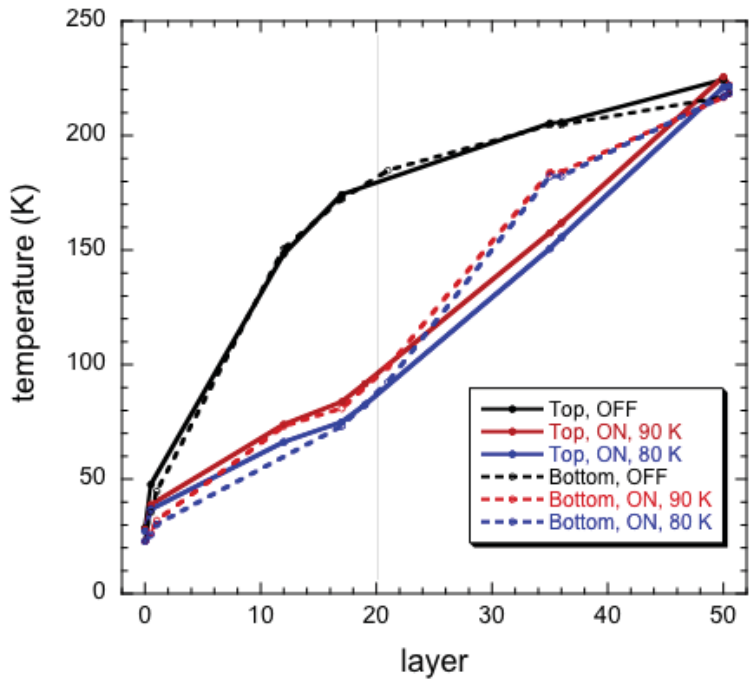

(a)

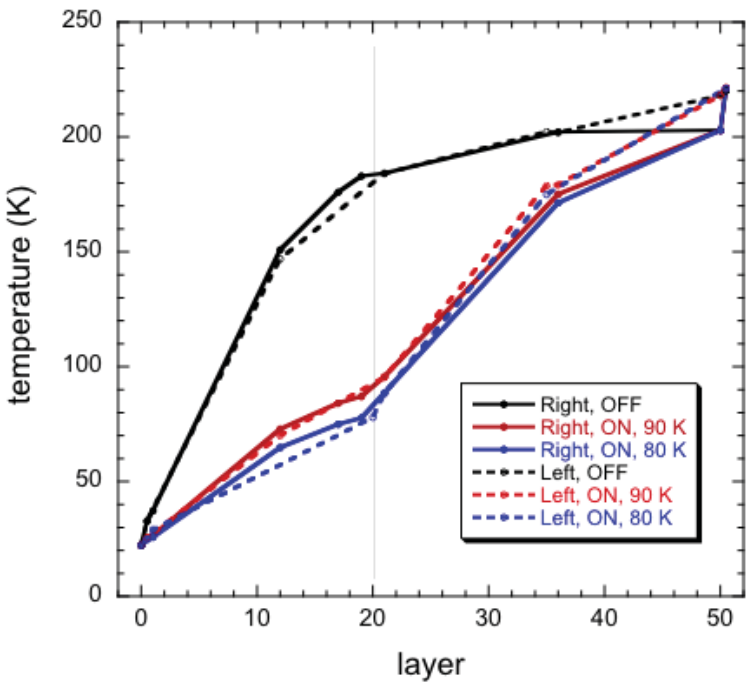

(b)

Figure 9. LB-MLI temperature profiles from LB-MLI testing, (a) top and bottom profiles, (b) left and right profiles along the tank equator.

Using the LB-MLI thermal model, it is found that a good least-squares fit to the temperature profiles cannot be made if it is assumed that $S F$ is temperature-independent (i.e., the same for cooler-off and cooler-on states). This suggests that something goes wrong with the model at low temperatures, specifically when the warm boundary temperature of the blanket is lowered to 80 or $90 \mathrm{~K}$. It turns out that in order to obtain a good fit to the data, radiative heat transfer must be much greater than what is predicted by the model. In other words, the lowtemperature degradation appears to be associated with the radiation term. The simplest way to modify the model is to assign different effective emissivities, $\varepsilon_{>90 \mathrm{~K}}$ and $\varepsilon_{<90 \mathrm{~K}}$, to the blanket in the cooler-off and cooler-on states, respectively. The best fit is obtained for $\varepsilon_{<90 \mathrm{~K}}$ an order of magnitude greater than $\varepsilon_{>90 \mathrm{~K}}: \varepsilon_{<90 \mathrm{~K}}=0.14$ and $\varepsilon_{>90 \mathrm{~K}}=0.02$. The modified model then describes reasonably well the LB-MLI heat leak data, both tank-applied and calorimeter coupon. Of course, this is an ad hoc fix, and doesn't explain what is physically happening to the reflective layers. There is, however, evidence that the IR transmissivity can increase sharply at low temperatures, an effect that is strongly dependent on the aluminum film thickness. For the tank-applied LB-MLI, as well as the calorimeter coupons, the nominal film thickness is $750 \AA$, which is on the thin side for commercially available doublealuminized mylar.

The results of these analyses are shown in Table 4 . There, $q_{\text {model }}=q_{\text {ideal }}$ is the heat flux given by the original model, with $S F=1 ; q_{\text {measured }}$ is calculated from the straight thermal balance on the tank, and $q_{\text {measured }}$ is the adjusted heat flux. The scale factor columns are $q_{\text {measured }} / q_{\text {ideal }}\left(=\right.$ Scale Factor) and $q_{\text {measured }} / q_{\text {ideal }}(=$ Scale Factor'). Note that the adjusted scale factor still depends on temperature, although now there is less divergence between the cooler-on and cooler-off values, and all three values are closer to 1, though muc is left to be desired. If the modified model is used with its postulated higher than expected low-temperature emissivity, then $S F=1.7=$ const. 
Table 4. LB-MLI performance after regression adjustments.

\begin{tabular}{|c|c|c|c|c|c|}
\hline Twarm $=220 \mathrm{~K}$ & $\begin{array}{l}\text { qmodel }^{2}\left(\mathrm{~mW} / \mathrm{m}^{2}\right)\end{array}$ & $\begin{array}{l}\text { qmeasured } \\
\left(\mathrm{mW} / \mathrm{m}^{2}\right)\end{array}$ & $\begin{array}{l}\mathbf{q}_{\text {measured }} \\
\left(\mathrm{mW} / \mathrm{m}^{2}\right)\end{array}$ & Scale Factor & Scale Factor' \\
\hline OFF (Test 3) & 116 & 207 & 170 & 1.8 & 1.5 \\
\hline ON, 90 K (5) & 21 & 92 & 55 & 4.4 & 2.6 \\
\hline ON, 80 K (1) & 19 & 79 & 42 & 4.3 & 2.3 \\
\hline
\end{tabular}

\section{E. Post Test Inspection and Foam Issues}

After both the thermal and acoustic tests were completed, the insulation systems were removed from the tanks and inspected for any damage that may have occurred either during the rapid pumpdown or acoustic testing. No damage was seen within any of the MLI systems or on the BAC shield. However, there was an abundancy of cracking between the Velcro strips that held the insulation in place and several divots that formed on the foam, mainly on the liquid hydrogen thermal test article. Two examples are shown in Figure 10.

Most of the damage was observed on the top and bottom of the tanks, in the conical portions of the foam. The foam thickness in these areas reached almost $10 \mathrm{~cm}$ (4 inches) in several places and had to be sprayed thicker in order to be trimmed down to the desired shape and size. Divoting was a common occurance during shuttle flights and was attributed as the main culprit of the loss of STS-107 (Columbia). ${ }^{18}$ Divots occur when a crack in the foam leads to a void while there is nitrogen (or air) that can be condensed into the void. When the pressure of the free stream (or in this case the vacuum chamber) is decreased rapidly, the liquid air/nitrogen cannot escape fast enough to remain in equilibrium, builds up pressure within the void until the foam on top of it gives way creating a divot. As such, it was a known risk that the project accepted even though NASA has gone through multiple efforts to reduce the risk.

Cracking in the foam is caused by differential shrinkage (from coefficient of thermal expansion) between the SOFI, primers to enhance SOFI adherence, and the base material. In this case, the tank was made from 304 Stainless Steel, while the SOFI has been optimized for performance on Aluminum 2219. Since Aluminum 2219 shrinks roughly $40 \%$ more than 304 Stainless Steel, more cracking would be expected on a stainless tank than on an Aluminum 2219 tank.

Several recommendations come out of discussions that encompassed the entire SOFI application process for reducing the likelihood of cracking. The first was to limit SOFI thicknesses in cryogenic application to less than one and a half inches (preferably less than one inch). The second recommendation was to attempt to avoid mechanical loading of the SOFI. The third was to design the system such that there were less sharp geometry features that could cause foam defects (voids).

\section{Conclusion}

The testing showed that LB-MLI is a viable option to support a broad area cooled shield based system for future exploration. This was shown through thermal and acoustic testing at the coupon and tank applied level. The acoustic testing showed with high confidence that there are no structural issues moving forward for a flight implementation of LB-MLI supporting a load. The thermal testing of the blanket showed that the LB-MLI blanket



(a)

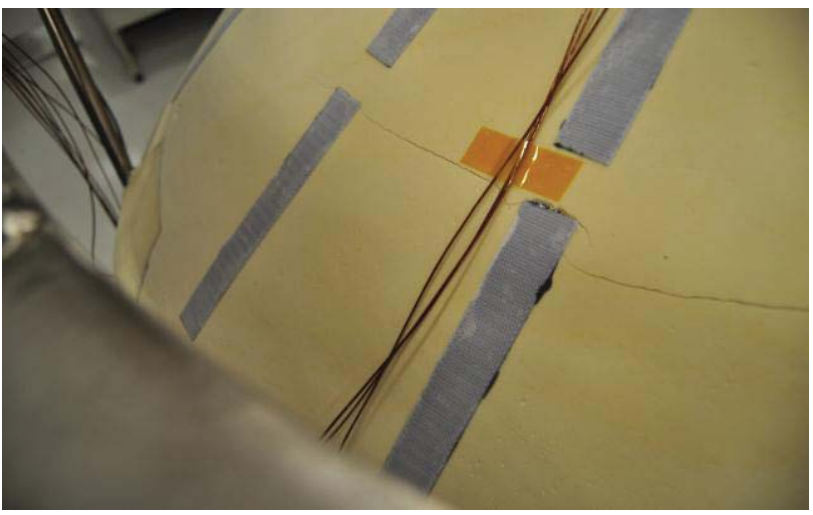

(b)

Figure 10. Post test foam inspection results. (a) A divot on the top of the thermal test tank. (b) cracking between Velcro strips on the acoustic test tank. 
was a high performance blanket and that the total heat load on the hydrogen tank was reduced significantly by operating the shield. While modeling of the LB-MLI system could be improved, a basis exists for moving forward with confidence in blanket thermal performance. Activiating the broad area cooling shield did lower the heat load through the MLI by over $50 \%$ with the shield at $90 \mathrm{~K}$ and by over $60 \%$ with the shield at $80 \mathrm{~K}$. It also reduced the heat load through the structural supports and fluid lines.

Issues seen with SOFI during testing lead to the questioning of whether SOFI with epoxied velcro attachment to a load such as MLI with at BAC shield can be acceptably used. Perhaps other methods of anchoring the MLI to the tank can be found or other insulation systems that can prevent the liquefaction of nitrogen. Alternatively, helium purge gasses will have to be used in cold MLI launch applications as it doesn't liquefy at $20 \mathrm{~K}$..

Based on the post test analysis of the temperature profile through the blanket, the emissivity (and possibly transmissivity) of thin vapor deposited aluminum films should be thoroughly investigated if modeling improvement is desired.

\section{Acknowledgments}

The authors would like to acknowledge the test teams at the Small Multipurpose Research Facility (Glenn Research Center - Tank Applied Thermal Testing), Bldg 4619 Acoustic Chamber (Marshall Space Flight Center Acoustic testing), and Environmental Systems Test Facility (Marshall Space Flight Center - Pre/Post-Acoustic Thermal Testing). Funding was provided by both the Cryogenic Propellant Storage and Transfer Technology Demonstration Mission and the Self-Supporting Multilayer Insulation Project within the Game Changing Technology Divison of the Space Technology Mission Directorate.

\section{References}

${ }^{1}$ Read, D.C., Parmley, R.T., et. al. "Status of the relativity mission superfluid helium flight dewar", Cryogenics, Vol 39, issue 4, 1999, pg. 369-379.

${ }^{2}$ Lee, J.H., "Thermal performance of a five year lifetime superfluid heium dewar for SIRTF", Cryogenics, Vol 30, Issue 3, 1990, pg. 166-172.

${ }^{3}$ Beech Aircraft Systems, "Vapor Cooled Shield" Drwg. 15548-3000, 1976.

${ }^{4}$ Plachta, D.W., Christie, R.J., Carlberg, E., and Feller, J.R., "Cryogenic Propellant Boil-Off Reduction System," Advances in Cryogenic Engineering, p. 1457, AIP, New York, 2008.

${ }^{5}$ Feller, J.R., Kashani, A., Helvensteijn, B.P.M., and Salerno, L.J., "Characterization of an Actively Cooled Metal Foil Thermal Radiation Shield," Advances in Crygenic Engineering, AIP, New York (2010).

${ }^{6}$ Feller, J.R., Plachta, D.W., Mills, G., and McLean, C., "Demonstration of a Cryogenic Boil-Off Reduction System Employing an Actively Cooled Thermal Radiation Shield," Cryocoolers 16, Kluwer Academic/Plenum Publishers, New York, 2011.

${ }^{7}$ Jurns, J. "MLI/BAC Venting Test at SMIRF Preliminary Test Data Review", December 2011.

${ }^{8}$ Smith, J.W., Wood, J.J., and Schnell, A.R., "Vibroacoustic Testing of Broad Area Cooling Panels", 2011 Space Cryogenics Workshop "Poised for the Future, Reflecting on the Past", NASA CP-2013-217479.

${ }^{9}$ Plachta, D.W., Christie, R.J., et.al. "Cryogenic Boil-off Reduction System Testing”, to be presented at the 2014 AIAA Propulsion and Energy Conference, Cleveland, OH, 2014.

${ }^{10}$ Dye, S., Kopelove, A., and Mills, G.L., "Integrated and Load Responsive Multilayer Insulation”, Advances in Cryogenic Engineering, Vol. 55B, ed. Weisend II, J.G., et. al., American Institute of Physics (Conference Procedings 1218), Melville, NY, 2010, pp. 946-953.

${ }^{11}$ Hamburger, J., "Insulation: Product Innovation, Call for Standards: Lightweight Spray-on Foam Insulation for Cryogenic Fuel Applications" Cold Facts, Vol. 27, No. 3, June 2011, pp. 8-9.

${ }^{12}$ Dye, S.A., Johnson, W.L., et.al. "Design, Fabrication, and Test of Load Bearing Multilayer Insulation to Support a Broad Area Cooled Shield" Presented at the 2013 Space Cryogenics Workshop, Girdwood, AK, 2013.

${ }^{13}$ Wood, J.J., "Acoustic and Thermal Testing of an Integrated Multilayer Insulation and Broad Area Cooling Shield System", Presented at the 2013 Space Cryogenics Workshop, Girdwood, AK, 2013.

${ }^{14}$ Hurd, J.A., Multilayer Insulation Testing at Variable Boundary Temperatures, Master's Thesis, Mechanical Engineering Department, Florida State University, Tallahasse, FL, 2013.

${ }^{15}$ Johnson, W.L., Heckle, K.W., and Hurd, J. "Thermal coupon testing of Load-Bearing Multilayer Insulation" Advances in Cryogenic Engineering, Vol. 59A, ed. Weisend II, J.G., et. al., American Institute of Physics (Conference Procedings 1573), Melville, NY, 2014, pp. 725.

${ }^{16}$ Johnson, W.L. "Recent Ground Hold and Rapid Depressurization Testing of Multilayer Systems", to be presented at the 2014 AIAA Propulsion and Energy Conference, Cleveland, OH, 2014.

${ }^{17}$ Johnson, W.L., Kelly, A.O., and Jumper, K.M., Two Dimensional Heat Transfer around Penetrations in Multilayer Insulation: Final Report, NASA-TP-2012-216315, 2012.

${ }^{18}$ Gehman Jr., H.W., Barry, J.L., et. al. Columbia Accident Investigation Board: Report Volume 1, Chapter 3, 2003. 